TÀI LIỆ THAM KHẢO

1. Hiệp hội ASEAN (2003). Hiệp định về Hệ thống hòa hợp ASEAN trong quản lý mỹ phẩm, Bản dịch của Cục Quản lý Dược, 2008.

2. Bộ Y tế (2011). Thông tư số 06/2011/TT-BYT Qưy định vê quản lý mỹ phẩm.

3. Bộ y tế (2021). Văn bản hợp nhất số $07 / \mathrm{VBHN}$ BỲ̛T Thông tư quy định về quản lý mỹ phẩm.

4. Chính phủ (2016). Nghi định số 93/2016/NĐ-CP Quy định điêuu kiện đối với các cơ sở sản xuất bán thành phẩm mỹ phẩm, thành phẩm mỹ phẩm và cơ sở đóng gói mỹ phẩm; trình tự, thủ tực cấp, cấp lai, điều chính, thu hồi Giấy chưưng nhận đư điêu kiện sản xuất mỹ phẩm.
5. Hoàng Thy Nhạc Vũ (2017). Thực trạng công tác cấp Số tiếp nhân Phiếu công bố mỹ phẩm của Sở $Y$ tế thành phố Hồ Chí Minh trong giai đoạn 2015-2016. Tạp chí Dược học, 496:66-70.

6. Hoàng Thy Nhạc vĩu, Trân Thị Ngoc Vân, Phạm Vĩnh Thăng (2016). Khảo sát đặc điểm các mỹ phẩm đăng ký quảng cáo tại thành phố Hồ Chí Minh giai đoạn 2014-2015. Tạp chí Y học Thực hành, 1027:6-9.

7. Bô Y tế (2018). Quyết đinh số 7866/QĐ-BYT Cổng bố thư tục hành chính mới ban hành, được sửa đổi, bổ sung trong lĩnh vực mỹ phẩm thuộc phạm vi chức năng quản lý của Bộ Y tê.

\title{
KẾT QUẢ PHẪU THUÂT GIẢI CHÈN ÉP ỐNG SỐNG QUA ỐNG BANH ĐIỀU TRI HẸP ỐNG SỐNG THẮT LƯNG DO THOÁI HÓA
}

\author{
Vi Trường Sơn*, Nguyễn Văn Sơn*, Phan Trọng Hậu**
}

\section{TÓM TẮT}

Mục tiêu: Đánh giá kết quả phẫu thuât giải phóng chèn ép qua ống banh điều trị hẹp ống sổng thắt lưng (HOSTL) do thoái hóa. Đối tượng và phương pháp: Nghiên cứu tiến cứu 62 bệnh nhân (BN) được chẩn đoán HOSTL do thoái hóa được phẫu thuật (PT) giải chèn ép ống sống qua ống banh thuật tại khoa $\mathrm{CTCH}$ côt sống - BVTWQĐ108 từ tháng 3/2015- 09/2016. Kết quả: $62 \mathrm{BN}$ (25 nam, 37 nữ), tuổi trung bình là $57,61 \pm 9,6$ (từ 32 tới 81 ) đã đước PT mở của sổ xương một bên giải chèn ép hai bển qua ống banh. Thời gian giải phóng chèn ép trung bình cho 1 mức đốt sống là $65,00 \pm 10,97$ phút, 02 mức là $85,88 \pm$ 18,04 phút. Kết quả xa sau PT được đánh giá theo thang điểm JOA (Japanese Orthopaedic Association score) tại thời điểm khám lại cuối cùng sau mổ trên 12 tháng 58/62 BN khám $(93,5 \%)$ Thời gian kiểm tra trung bình: $33,47 \pm 16,89$ tháng (12-60). Rất tốt: 22 (37,9\%), tốt: $31(53,4 \%)$, trung bình: $3(5,1 \%)$, kém: 2 (3,6\%). Đánh giá cải thiện triệu chứng lâm sàng sau can thiệp tại thời điểm khám cuối cùng: điểm đau lưng VAS (Visual Analogue Scale) trước mổ 5,03 $\pm 1,24$ khi khám lai là $0,67 \pm 1,09$, điểm đau chân VAS trước mổ là 7,23 $\pm 0,98$ khi khám lại là $0,95 \pm 1,42$, ODI (Oswestry Disability Index 2.0) trước mổ 66,32 $\pm 5,39$ khi khám lại là $17,47 \pm 11,77$, điểm JOA trước phẩu thuật là $11,29 \pm 1,35$ khi khám lại là $24,39 \pm 2,70$. Đánh giá sự gia tăng kích thước của ống sống trên phim công hưởng từ (CHT) sau PT giải chèn ép tai thời điểm khám cuối cùng 35/62 BN với sự thay đổi có ý nghĩa thống kê ( $p<0,001)$ : đường kính trước sau ống sống (ĐKTS) là 4,82 $\pm 1,65$ mm (trước PT:

*Bệnh viện Đa khoa Phú Tho

**Bệnh viện TƯQĐ108

Chịu trách nhiệm chính: Vi Trường Sơn

Email: sonha.tpviettri@gmail.com

Ngày nhận bài: $28 / 5 / 2021$

Ngày phản bienj khoa học: 20/6/2021

Ngày duyệt bài: 19/7/2021
$6,43 \pm 1,34 \mathrm{~mm}$, sau PT:11,25 $\pm 1,59 \mathrm{~mm}$ ) và diện tích ống sống (DTOS) 73,06 $\pm 18,80$ mm² (trước PT: $49,29 \pm 15,09$, sau PT: $122,35 \pm 25,79)$. Biến chứng trong mổ: rách màng cứng: $02(3,2 \%)$, tụ máu ngoài màng cứng $01(1,6 \%)$. Kết luận: Phẫu thuật giải chèn ép ống sống qua ống banh dưới kính vi phẫu thuật là phương pháp can thiệp ít xâm lấn, hiệu quả và an toàn trong điêu trị bệnh lý HOSTL do thoái hóa.

Tư khóa: Hẹp ống sống do thoái hóa, phẫu thuật can thiệp tối thiểu

\section{SUMMARY \\ THE EVALUATION OF UNILATERAL APPROACH FOR BILATERAL DECOMPRESSION OF DEGENNERATIVE LUMBAR SPINAL STENOSIS WITH TUBULAR RETRACTOR SYSTEM}

Aims: To assess the results of minimally invasive surgery approach for degenerative lumbar spinal stenosis. Methods: From 03/2015 to 09/2016 the surgery was performed on 62 patients ( 25 men and 37 women; 32-81years; median age, 57,61 $\pm 9,6$ years). We carried out bilateral interlaminar fenestration and unroofing for the decompression of nerve roots by using a unilateral approach. Result: Average of surgical time was $65,00 \pm 10,97$ minutes for per level, $85,88 \pm 18,05$ minutes for two levels. Surgical results were classified by JOA score at the last follow up, $58 / 62$ patients, average time 33,47 $\pm 16,89$ months. Excellent: $22(37,9 \%)$, good: $31(53,4 \%)$, fair: 3 $(5,1 \%)$, poor: $2(3,6 \%)$. VAS back pain improved from $5,03 \pm 1,24$ to $0,67 \pm 1,09$, VAS radicular pain improved from $7,23 \pm 0,98$ to $0,95 \pm 1,42$, ODI improved from $66,32 \pm 5,39$ to $17,47 \pm 11,77$, JOA improved from $11,29 \pm 1$ to $24,39 \pm 2,70$. The increasing of spinal canal on MRI at the last follow up (35/62 patients) significant difference $(p<0,001)$ : A$P$ diameter: 4,82 $\pm 1,65 \mathrm{~mm}$ (pre-op: 6,43 \pm 1.34 $\mathrm{mm}$; post-op: $11,25 \pm 1,59 \mathrm{mmm})$; Dural sac crosssectional area: 73,06 $\pm 18,80 \mathrm{~mm}^{2}$ (pre-op:49,29 \pm 15,09, post-op: $122,35 \pm 25,79)$. Complications: dural tear were $2(3,2 \%)$ and epidural hematoma in 
$01(1,6 \%)$. Conclusion: Minimally invasive surgery is safe, effective and lower rate of complication for degenerative lumbar spinal stenosis.

Key words: Degenerative lumbar spinal stenosis, minimally invasive surgery

\section{I. ĐĂT VẤN ĐỀ}

Do tuổi thọ của người dân không ngừng tăng cao nên bệnh lý HOSTL do thoái hóa ngày càng phổ biến ở lứa tuổi trên 65 và ảnh hưởng nhiều đến chất lượng cuộc sống của người bệnh. Triệu chứng lâm sàng chính của bênh là đau lưng, tê chân và dấu hiệu đau cách hồi thần kinh. Trong điều trị HOSTL thì PT giải chèn ép được thừa nhận là giải pháp có tính ưu việt khi điều trị nội khoa thất bại [2]. Phẫu thuật cắt cung sau giải chèn ép (Laminectomy) từ lẩu đã được sử dụng trong điều trị HOSTL với ưu điểm bộc lộ rộng rãi và giải phóng rễ thần kinh bị chèn ép tối đa với tỷ lê thành công $62-70 \%$ [3]. Tuy nhiên do hạn chế cắt bỏ những thành phần quan trọng tham gia làm vững cột sống như lam cung sau, các dây chằng trên gai và liên gai, bóc tách điểm bám của các cơ dựng sống dấn tới đau thắt lưng thứ phát do xơ hóa cơ cạnh sống, mất vững hoặc trượt đốt sống thứ phát sau mổ [4],[7]. Để khắc phục những nhược điểm đó phương pháp PT giải chèn ép ống sống qua ống banh (Caspar retractor) mở cửa sổ một bên nhưng giải chèn ép hai bên dưới kính vi phẫu thuật với kích thước vết mổ $n h o ̉(\approx 2 \mathrm{~cm})$, lượng máu mất ít, giảm lượng thuốc giảm đau dùng sau mổ và rút ngắn thời gian hậu phẫu. Ngoài $\mathrm{ra}$, bảo toàn sự nguyên vẹn cấu trúc giải phẫu các mấu khớp, điểm bám cơ cạnh sống và dây chằng bên ngoài ống sống ở bên đối diện mà vẫn đảm bảo giải chèn ép rộng rãi cả hai bên của ống sống [5]. Ở Việt Nam hiện nay kỹ thuật này còn tương đối mới và rất ít bệnh viện áp dụng vì vậy chúng tôi thực hiện đề tài này nhằm báo cáo và đánh giá kết quả của phẫu thuật này.

\section{II. ĐỐI TƯợNG VÀ PHƯƠNG PHÁP NGHIÊN CỨU}

1. Đối tượng nghiên cứu: 62 bệnh nhân được chẩn đoán HOSTL do thoái hóa được phẫu thuật bằng kỹ thuât giải chèn ép ống sống qua ống banh từ tháng 03/2015 đến tháng 09/2016 tại Khoa CTCH cột sống - BVTWQĐ 108.

\section{> Tiêu chuần lưa chon:}

- Tiêu chuẩn chẩn đoán: BN được chẩn đoán HOSTL do thoái hoá với biểu hiện lâm sàng là dấu hiệu đau cách hồi thần kinh đi kèm với đau lưng và tê chân. Trên phim $\mathrm{CHT}$ thường quy có hình ảnh HOSTL phù hợp với tổn thương trên lâm sàng với DTOS $\leq 76 \mathrm{~mm}^{2}$ (mức độ hẹp nặng).
- BN có chỉ định phẫu thuật giải chèn ép ống sống qua ống banh

+ HOSTL có thương tổn thần kinh tiến triển

+ HOSTL có hội chứng đuôi ngựa

+ HOSTL có đau kiểu rễ, điều trị nội khoa 3 tháng không đáp ứng

- Được phẫu thuật thống nhất một phương pháp giải chèn ép ống sống qua ống banh ở một hoặc hai tầng

> Tiêu chuâin loại trừ:

- HOSTL kèm trượt đốt sống hoặc mất vững

- HOSTL có kèm theo các bệnh toàn thân phối hợp không cho phép phẫu thuật

- HOSTL do chấn thương, viêm hay khối u, đã phẫu thuật trước đó.

2. Phương pháp nghiên cứu: Nghiên cứu thử nghiệm lâm sàng tiến cứu, mô tả không đối chứng.

\section{Nội dung nghiên cứu:}

- Thời gian phẩu thuật cho mỗi tầng bị bệnh, thời gian hậu phẫu (tính từ ngày mổ đến khi ra viện), số tầng và vị trí phẫu thuật.

- Theo dõi và đánh giá sau mổ: so sánh các dấu hiệu lâm sàng đau lưng VAS, VAS chân, ODI và JOA. Kết quả phẫu thuật theo JOA [Tỷ lệ bình phuc $=$ (Điểm khám lai - điểm trước mổ)/ (29điểm trước mổ) x 100\%. BN được đánh giá kết quả theo JOA: rất tốt (>75\%), tốt (50\%-75\%), trung bình ( $25 \%-50 \%)$ và xấu (<25\%)].

- So sánh đường kính trước sau và diện tích ống sống trên phim $\mathrm{CHT}$ trước và sau can thiệp thông qua phầm mềm Onis 2.5.

4. Phương pháp phẫu thuật: Bệnh nhân được gây tê tủy sống, nằm sấp. Sử dung hệ thống ống banh Quadrant kết hợp với kính vi phẫu để thực hiện giải chèn ép. Vị trí đốt sống cần giải chèn ép được kiểm tra bằng chiếu Xquang tại phòng mổ, đánh dấu vị trí và độ dài vết mổ trên da. Chiều dài vết mổ khoảng $2 \mathrm{~cm}$ đối với giải chèn ép 1 mức và khoảng $2.5 \mathrm{~cm}$ đối với giải chèn ép 2 mức đốt sống. Tách điểm bám của cơ canh sống vào lam cung sau và bao khớp. Luồn các ống banh bóc tách cớ, dùng khoan mài mở cửa sổ xương (laminotomy) cùng bên tới điểm bám của dây chằng vàng. Cắt dây chằng vàng và một phần mấu khớp phì đại. Kiểm tra sự di động của rễ thần kinh sau khi giải phóng chèn ép. Nghiêng ống banh và nghiêng bàn mổ để tiến hành giải phóng chèn ép bên đối diện. Mài phần dưới của gai sau, qua đó mài phần xương phía dưới của lam cung sau (undercutting laminotomy) bên đối diện. Mấu khớp bên đối diện phì đại làm hẹp ngách bên cũng được mài một phần làm rộng đường đi của rễ thần kinh. Lấy bỏ dây chằng vàng phì đại bên đối diện. Kiểm tra ống sống và rề thần 
kinh bên đối diện thấy hết chèn ép. Giải phóng chèn ép được coi là đạt yêu cầu khi lam cung sau được mở tới hết chố bám của dây chằng vàng ở cả hai bên, lấy bỏ hết phần dây chằng vàng phì đại làm hẹp ống sống và các rễ thần kinh hai bên di động được dể dàng.

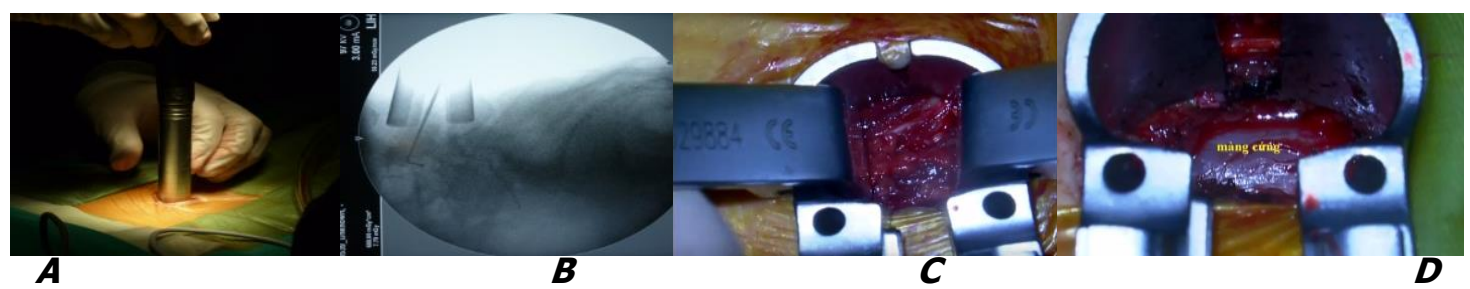

Hình 2.1: Mô tả kỹ thuật giải chèn ép ống sống qua ống banh

A: Thi đưa các ống nong, B: Kiểm tra vị trí phẫu thuật dưới Xquang C: Ống banh được mở rộng; D: Màng cứng được bộc lộ sau khi cắt bỏ dây chằng vàng

\section{KẾT QUẢ NGHIÊN CỨU}

3.1. Đặc điểm chung: Kết quả $62 \mathrm{BN}$ tuổi trung bình 57,61 \pm 9,6 (32-81) với tỷ lệ 25 nam/ 37 nữ. Thời gian mắc bệnh trung bình 23,39 tháng đã điều trị nội khoa 5,61 tháng trước phẫu thuật. Số BN được PT 1 tầng là 45; 2 tầng là 17 trong đó vị trí được phẫu thuật cụ thể L3-L4:12, L4-L5: 60, L5-S1: 07 (biểu đồ 3.1)

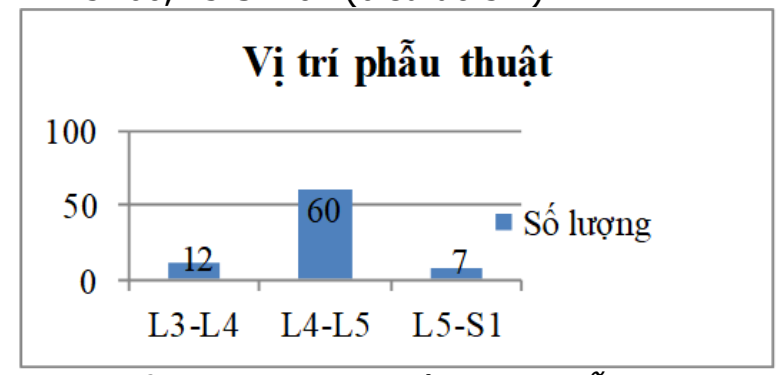

\section{Biểu đồ 3.1. Đăc điểm vị trí phẫu thuật}

\subsection{Kết quả phầu thuật}

- Thời gian tiến hành mổ cho 1 tầng 65,0 $\pm 10,97$ phút, 02 tầng là $85,88 \pm 18,04$ phút. Thời gian hậu phấu $6,03 \pm 2,55$ ngày, thời điểm cuối cùng trung bình $33,47 \pm 16,89$ tháng. Sự gia tăng về kích thước của ống sống tại thời điểm khám cuối cùng $(35 / 62 \mathrm{BN})$ trên phim $\mathrm{CHT}$ : ĐKTS trước và sau PT là $4,82 \pm 1,65 \mathrm{~mm}$, DTOS $73,06 \pm 18,80 \mathrm{~mm}^{2}$ với $\mathrm{p}<0,001$ (bảng 3.1). Kết quả PT theo JOA: rất tốt 37,9 \%; tốt 53.4\%, trung bình $5,1 \%$, kém 3,6\% (bảng 3.2). Thay đổi của các triệu chứng lâm sàng đau lưng, tê chân, chỉ số ODI và JOA tại thời điểm khám cuối cùng (bảng 3.3): VAS lưng trước mổ $5,01 \pm 1,24$, thời điểm khám cối cùng $0,67 \pm 1,09$; VAS chân trước mổ $7,21 \pm 0,98$, thời điểm khám cối cùng 0,95 $\pm 1,42$; điểm JOA trước mổ $11,19 \pm 1,35$, tại thời điểm khám cối cùng $24,39 \pm 2,70$; chỉ số ODI trước mổ 65,32 $\pm 5,39 \%$, tại thời điểm khám cối cùng $17,47 \pm 11,77 \%$. Trong nghiên cứu của chúng tôi không có ca nào phải truyền máu trong mổ. Tỷ lệ tai biến rách màng cứng gặp 2 ca $(3,2 \%)$, mất vững sau mổ có 01 trường hợp $(1,7 \%)$.

Bảng 3.1. Thay đổi kích thước ống sống

\begin{tabular}{|c|c|c|c|c|c|}
\hline Chỉ số & \multicolumn{2}{|c|}{ Trước PT } & $\begin{array}{c}\text { Khám } \\
\text { cuối cùng }\end{array}$ & $\begin{array}{l}\text { Hiệu số } \\
\text { thay đổi }\end{array}$ & ốn \\
\hline $\begin{array}{l}\text { DTOS } \\
\left(\mathrm{mm}^{2}\right)\end{array}$ & \multicolumn{2}{|c|}{$49,29 \pm$} & $\begin{array}{c}122,35 \pm \\
25,79\end{array}$ & $73,06 \pm$ & \begin{tabular}{l|l} 
\pm \\
0,001
\end{tabular} \\
\hline $\begin{array}{l}\text { ĐKTS } \\
(\mathrm{mm})\end{array}$ & \multicolumn{2}{|c|}{$\begin{array}{c}6,43 \pm \\
1,34\end{array}$} & $\begin{array}{c}11,25 \pm \\
1,59\end{array}$ & $\begin{array}{c}1,82 \pm \\
1,65\end{array}$ & 0,001 \\
\hline \multirow{2}{*}{\multicolumn{6}{|c|}{$\begin{array}{cc}\text { Tống (\%) } & 35(56,4 \%) \\
\text { Báng 3.2. Kêt quả phấu thuật theo JOA }\end{array}$}} \\
\hline & & & & & \\
\hline Kết quả & $\begin{array}{l}\text { Rất } \\
\text { tốt }\end{array}$ & Tốt & \begin{tabular}{|c|c|} 
Trung \\
bình
\end{tabular} & Kém & Tổng \\
\hline $\begin{array}{c}\text { Số lượng } \\
\text { (n) }\end{array}$ & 22 & 31 & 03 & 02 & 58 \\
\hline Tỷ lệ \% & 37,9 & 53,4 & 5,1 & 3,6 & 100,0 \\
\hline
\end{tabular}

Bảng 3.3. Thay đối triệu chứng lâm sàng sau phâu thuật

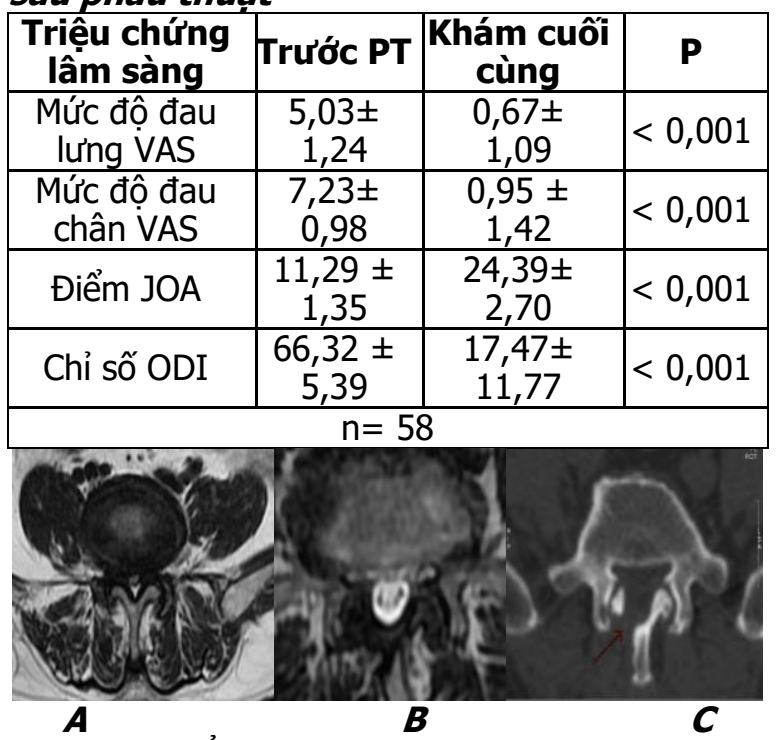

Hình 3.1. Anh $B N$ minh họa $B N$ Đinh Quang $H$. 65T. Chẩn đoán HOS L4-L5

A: CHT trước mố; B: CHT sau mô; C: cắt lớp vi tính sau mố (vị trí cắt cung sau mũi tên) 


\section{BÀN LUÂNN}

1. Đắc điểm chung. Trong tổng số $62 \mathrm{BN}$ của chúng tôi có độ tuổi trung bình là 58 (25nam/37 nữ) trong đó thấp nhất là 32 và cao nhất là 81 , nhóm tuổi từ $50-70$ chiếm tỷ lệ khá cao tới $70 \%$. Nghiên cứu của các tác giả Koichi Iwatsuki [4] cho thấy tỷ lệ tương tự. Do đặc điểm HOSTL do thoái hóa là bệnh mãn tính nển $\mathrm{BN}$ thường đến viện muộn thời gian mắc bệnh trung bình là 23,39 tháng, thời gian điều trị trước khi can thiệp là 5,61 tháng.

\section{Phẫu thuật giải chèn ép ống sống qua ống banh \\ Đặc điểm lâm sàng. HOSTL do thoái hóa là} tình trạng lòng ống sống bị hẹp do tổ chức xung quanh xâm lấn và chèn ép thần kinh vì vậy $\mathrm{PT}$ làm rộng ống sống giải phóng chèn ép thực sự cần thiết đối với những BN điều trị nội khoa thất bại. Theo Atlas và cộng sự [7] phẫu thuật giúp cải thiện triệu chứng đau, tê chân hơn rất nhiều so với điều trị nội khoa. Với 60 BN được can thiệp ở vị trí L4-L5 điều đó chứng tỏ đây là vị trí hay gặp trên lâm sàng và liên quan đến đặc điểm giải phẫu và cơ chế bệnh sinh.

Đặc điểm cận lâm sàng. Việc đánh giá gia tăng kích thước ống sống sau can thiệp PT trên phim $\mathrm{CHT}$ ở thời điểm thăm khám cuối cùng của 35/62 BN cho thấy có sự gia tăng về kích thước của ống (ĐKTS: 4,82 $\pm 1,65 \mathrm{~mm}$ và DTOS: 73,06 $\pm 18,80 \mathrm{~mm}^{2}$ ) đã chứng tỏ hiệu quả của kỹ thuật trong viêc mở cửa sổ xương, cắt bỏ dây chằng vàng và bản trong của lam cung sau bên đối diện từ đó giúp cho rễ thần kinh và tủy sống được giải chèn ép dẫn tới giảm triệu chứng trên lâm sàng.

\section{Đăc điểm phẫu thuât}

- Có rất nhiều kỹ thuật giải chèn ép được áp dụng trong điều trị HOSTL với mục tiêu giải chèn ép thần kinh tối đa đồng thời bảo tồn tối đa cấu trúc giải phẫu và chức năng của cột sống sau mổ. Phẫu thuật cắt cung sau rộng rãi được cho là giải chèn ép thần kinh tối đa với tỷ lệ thành công khoảng 64\%[8] tuy nhiên do làm tổn thương các yếu tố như cung sau, dây chằng, điểm bám cơ dựng sống dẫn đến đau lưng và mất vững sau mổ. Phẫu thuật cắt một phần cung sau giải chèn ép (Laminotomy) ra đời với tỷ lệ thành công $84 \%$ và hạn chế tối đa mất vững sau mổ tuy nhiên PT này vẫn phải bóc tách điểm bám của các cơ dẫn tới đau lưng sau mổ do xơ hóa cơ dựng sống. Do HOSTL thường gặp ở người cao tuổi với nhiều bệnh lý phối hợp đồng thời xu hướng can thiệp tối thiểu đang ngày càng trở nên phổ biến nên phương pháp giải chèn ép qua ống banh (Caspar retractor) dưới kính vi phầu thuật ra đời với những ưu điểm là tỷ lệ thành công $87 \%$ [6], can thiệp tối thiểu với vết mổ nhỏ, không bóc tách điểm bám của cơ dựng sống vào lam cung sau, giải phóng chèn ép tối đa nhưng vẫn bảo tồn nguyên vẹn cơ bên đối diện, hạn chế tối đa sự xơ hóa cơ cạnh sống được cho là có liên quan đến đau lưng sau mổ. Ngoài ra các yếu tốt như gai sau, dây chằng liên gai, dây chằng trên gai có vai trò quan trọng trong việc tham gia làm vững cột sống cửng không bị cắt bỏ, hạn chế mất vững sau mổ.

- Kết quả xa sau PT được đánh giá theo thang điểm của JOA tại thời điểm khám lại cuối cùng sau mổ trên 12 tháng 58/62 BN khám $(93,5 \%)$ với thời gian kiểm tra trung bình: 33,47 $\pm 16,89$ tháng: rất tốt $37,9 \%$; tốt $53.4 \%$, trung bình $5,1 \%$, kém $3,6 \%$. Các chỉ số VAS, ODI và JOA sau mổ cải thiện rõ rệt so với trước mổ có ý nghĩa thống kê với $p<0,001$ (bảng 3.3) đồng thời tăng lên theo thời gian có thể nói kỹ thuật can thiệp rất hiệu quả trong giải quyết các triệu chứng chèn ép thần kinh và cải thiện chất lượng cuộc sống của người bệnh.

- Tai biến rách màng cứng: nghiên cứu ghi nhận 02 bệnh nhân bị rách màng cứng. Chúng tôi đã sử dụng vật liệu BioGlu để tạo hình lại màng cứng trong mổ và không bị rò dịch não tủy sau mổ. Đây là tai biến hay gặp phụ thuộc rất nhiều vào kinh nghiệm của phẩu thuật viên.

- Nghiên cứu ghi nhận 01 ca $(1,6 \%)$ bị tụ máu ngoài màng cứng sau PT. BN xuất hiện tể và yếu 2 chân (cơ lực $3 / 5$ ), đau lưng nhiêu sau can thiệp ngày thứ 2 , sonde dẫn lưu vết mổ không ra dịch, chụp lại CHT sau phẫu thuật có hình ảnh máu tụ ngoài màng cứng cùng bên với vị trí đặt ống banh. Tiến hành kiểm tra lại vết mổ thấy máu chảy ra từ mạch máu quanh màng cứng, tiến hành cầm máu bằng dao đốt lưỡng cực Bipoler và Surgicel, BN ra viện có di chứng yếu nhe 2 chân (cơ lực 4/5). Thông qua trường hợp trền cho thấy, trong kỹ thuật giải phóng chèn ép qua ống banh mặc dù được kiểm soát chảy máu rất kỹ và lượng máu mất trong mổ rất ít nhưng việc kiểm tra và cầm máu kỹ trước khi rút ống banh là rất cần thiết. Tác giả Grath gặp 02 ca $(4,4 \%)$ tụ máu ngoài màng cứng sau PT giải phóng chèn ép qua ống banh cho 45 BN [1]

\section{KẾT LUÂ̂N}

- Phẫu thuật giải chèn ép ống sống qua ống banh dưới kính vi phẫu là phương pháp can thiệp tối thiểu hiệu quả và an toàn với tỳ lệ thành công $91,3 \%$, tai biến thấp rách màng cứng $2 \mathrm{ca}$ 
(3,2\%), tụ máu ngoài màng cứng 01 ca $(1,6 \%)$ không có BN phải truyền máu trong mổ.

- Đây là phương pháp không những giải phóng chèn ép thân kinh tối đa mà còn bảo tồn được các cấu trúc quan trọng như cơ cạnh sống, khớp liên đốt, hệ thống dây chằng dẫn tới hạn chễ tỷ lệ đau lưng và mất vững cột sống sau phẫu thuâtt.

\section{TÀl LIẸU THAM KHẢO}

1. Grath L. B., White-Dzuro G. A., Hofstetter C. P. (2019). "Comparison of clinical outcomes following minimally invasive or lumbar endoscopic unilateral laminotomy for bilateral decompression". Journal of Neurosurgery and Spine, 30 (4), pp.491-499.

2. Gu, Guangfei, Hailong Zhang, Shisheng He, Qingsong Fu, Xiaobing Cai, Xu Zhou, Xiaolong Shen, and Xin Gu. 2016. "A Novel Classification and Minimally Invasive Treatment of Degenerative Lumbar Spinal Stenosis" Turkish Neurosurgery 26 (2): 260-67.

3. Hwang, Sang-won, Seung-chul Rhim, and Sung-woo Roh. 2008. "Outcomes of Unilateral Approach for Bilateral Decompression of Lumbar
Spinal Stenosis : Comparison between Younger and Geriatric Patients" 5 (2): 51-57.

4. Iwatsuki, Koichi, Toshiki Yoshimine, and Masanori Aoki. 2007. "Bilateral Interlaminar Fenestration and Unroofing for the Decompression of Nerve Roots by Using a Unilateral Approach in Lumbar Canal Stenosis." Surgical Neurology 68 (5): 487-92.

5. Kerr SM, Tannuory C, White AP. 2007. "The Role of Minimally Invasive Surgery in the Lumbar Spine." Current Orthopaedics 17: pp 183-89.

6. Lauryssen, Carl. 2010. "Technical Advances in Minimally Invasive Surgery - Direct Decompression for Lumbar Spinal Stenosis." Spine 35 (26 Suppl): S287-93.

7. Nomura, Kazunori, and Munehito Yoshida. 2017. "Assessment of the Learning Curve for Microendoscopic Decompression Surgery for Lumbar Spinal Canal Stenosis through an Analysis of 480 Cases Involving a Single Surgeon." Global Spine Journal 7 (1): pp 54-58.

8. Pao, Jwo Luen, Wein Chin Chen, and Po Quang Chen. 2009. "Clinical Outcomes of Microendoscopic Decompressive Laminotomy for Degenerative Lumbar Spinal Stenosis." European Spine Journal 18 (5): pp 672-78.

\section{NGHIÊN CỨU ỨNG DƯNG VẠT DA CÂN NHÁNH XUYÊN ĐộNG MACH CỔ NÔNG ĐIỀU TRI SEO CO KÉO VÙNG CẰM Cổ VÀ LOÉT MAN TÍNH VÙNG ĐİNH CHẨM}

\section{TÓM TẮT}

Mục tiêu: Nghiên cứu ứng dụng vạt da cân mjamhins xuyên động mạch cổ nông điều trị sẹo co kéo vừng cằm cổ và loét mạn tính vùng đỉnh chẩm. Đối tương và phương pháp: Nghiên cứu tiến hành phấu thuật trên 25 bệnh nhân tuổi trung bình 36 tuổi (24 $\mathrm{BN}$ có seo co kéo vùng cằm cổ và $01 \mathrm{BN}$ có loét man tính vùng chẩm), được phẫu thuật sử dụng vạt da cần nhánh xuyên đông mạch cổ nông che phủ tốn khuyết tại trung tâm Phẫu thuật tạo hình, thẩm mỹ và tái tạo, Viện Bỏng Quốc Gia từ tháng10 năm 2014 đến tháng 06 năm 2020. Kết quả: 25 vạt da nhánh xuyên động mạch cổ nông đã được sử dụng. Kích thước vạt da có chiều dài trung bình là $23,36 \mathrm{~cm}$ và chiều rộng trung bình là 10,56cm, kích thước vạt da lớn nhất lấy được là $30 \times 12 \mathrm{~cm}$. Góc xoay vat da trung bình là 84,2 độ. Có 24 vạt chiếm $96 \%$ sống tốt sau phẫu thuật và liền thì đâu, có 1 vat da hoai tử một phần. Ghi nhân có sự cải thiện về góc ngữa đâuu sau phẫu thuật: trước phấu

\footnotetext{
${ }^{1}$ Bệnh viện Trưng Vương TP HCM ${ }^{2}$ Họ viến Quân y

Chịu trách nhiệm chính: Võ Anh Minh

Email: voanhminh64@gmail.com

Ngày nhận bài: $1 / 6 / 2021$

Ngày phản biên khoa học: 26/6/2021

Ngày duyệt bài: 15/7/2021
}

Võ Anh Minh'1 Vũ Quang Vinh ${ }^{2}$, Nguyễn Gia Tiến ${ }^{2}$

thuật: 93 độ, sau mổ 1-3 tháng 114,4 độ và sau mổ 6 đến 24 tháng là 129 độ. Kết luận: Vạt da cân nhánh xuyên động mạch cổ nống ứng dụng trong điêu trị cho sẹo co kéo vùng cằm cố và loét mạn tính vùng đỉnh chẩm cho kết quả tốt.

Tư khoá: Vạt da cân nhánh xuyên, động mạch cổ nông, sẹo co kéo vùng cổ

\section{SUMMARY}

TREATMENT OF CERVICAL SCAR

CONTRACTURES AND OCCIPITAL CHRONIC ULCER USING SUPERFICIAL CERVICAL ARTERY PERFORATOR FLAP

Objectives: Research on the superficial cervical artery perforator flap in the treatment of cervical scar contractures and apex occipital chronic ulcer. Subjects and methods: A descriptive study of case series performed on 25 patients with cervical scar contractures and apex occipital chronic ulcer who were operated on using superficial cervical artery perforator flap at the Center of Plastic, Aesthetic and Reconstructive Surgery, National Institute of Burns from october 2014 to june 2020 Indications for surgery in these patients are limit movement of cervical, loss of aesthetics and chronic ulcers. Results: We obtained 24 patients with cervical scar contractures and 01 patient with oppicital chronic ulceration. Regarding the clinical characteristics, we 